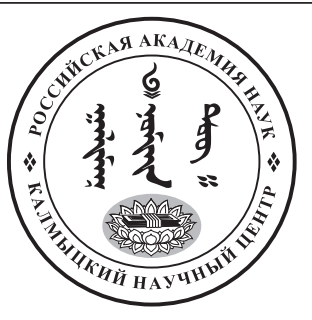

Published in the Russian Federation

Oriental Studies (Previous Name: Bulletin of the Kalmyk Institute

for Humanities of the Russian Academy of Sciences)

Has been issued as a journal since 2008

ISSN: 2619-0990; E-ISSN: 2619-1008

Vol. 13, Is. 1, pp. 64-74, 2020

DOI: $10.22162 / 2619-0990-2020-47-1-64-74$

Journal homepage: https://kigiran.elpub.ru

УДК 390 (571.52)+392.1 (571.52)

\title{
Женские прически и накосные украшения тувинцев: историко-этнографический очерк
}

\author{
Елена Валерьевна Айыжы ${ }^{1}$, Роланда Биче-ооловна Ховальг ${ }^{2}$ \\ ${ }^{1}$ Тувинский государственный университет (д. 36, ул. Ленина, 667000 Кызыл, Российская \\ Федерация) \\ кандидат исторических наук, доцент \\ iD 0000-0002-4289-3543. E-mail: aiygy@mail.ru
}

${ }^{2}$ Национальный музей имени Алдан-Маадыр Республики Тыва (д. 30, ул. Титова, 667000 Кызыл, Российская Федерация)

главный хранитель

iD 0000-0002-6390-7406. E-mail: hovrol@mail.ru

(C) КалмНЦ РАН, 2020

(C) Айыжы Е. В., Ховалыг Р. Б., 2020

Аннотация. Введение. Статья посвящена исследованию женских причесок и накосных украшений тувинцев, выявлению их типологии и особенностей. Украшения как компонент материальной и одновременно духовной культуры народа в целом ряде своих элементов - материале, технологии изготовления, художественном оформлении, сюжетах и символике, терминологии и в мировоззренческих представлениях - устойчиво сохраняют ценные сведения историко-этнографического характера и свое семантическое значение. Целью статьи является исследование традиционных типов причесок и полагающихся к ним накосных украшений тувинцев в историко-этнографическом аспекте, что позволит выявить данные, касающиеся как древнейших верований и культов, обычаев и обрядов тувинцев, так и проблем этногенетических и этнокультурных связей между народами Центральной Азии. До настоящего времени задача составления типологии и выявления этнокультурных параллелей в культуре традиционных причесок и украшений народов Центральной Азии не ставилась, либо вопросы, связанные с этой темой, рассматривались фрагментарно, частично. Малоизученность проблемы и возросший интерес в условиях глобализации к культуре тувинского этноса обусловили актуальность предпринимаемого исследования. В статье использованы современные междисциплинарные методы и реализован комплексный подход. Результатьл: обобщены результаты этнографических исследований и анализа полевых и архивных материалов по составлению и типологизации женских причесок и накосных украшений тувинцев с конца XIX по XXI в., а также освещены некоторые элементы обрядовой практики и особенности украшений. Показано, что в традициях субэтнических групп и районов Тувы имелись особенности, которые отличали их от других. Вместе с тем можно выявить семь основных типов причесок девочки и женщины, которые являлись маркерами возрастных групп. Накосные украшения также отли- 
чались спецификой для разных возрастных групп и маркировали статус девушки и женщины. Ключевые слова: типы женских причесок, мужские прически, украшения, накосные украшения, тюрко-монгольский мир, тувинцы

Благодарность. Исследование выполнено при финансовой поддержке РФФИ в рамках научного проекта № 19-012-00073.

Для цитирования. Айыжы Е. В., Ховалыг Р. Б. Женские прически и накосные украшения тувинского этноса: этнографические исследования // Oriental Studies. 2020. Т. 13. № 1. С. 64-74. DOI: $10.22162 / 2619-0990-2020-47-1-64-74$

UDC $390(571.52)+392.1(571.52)$

\title{
Tuvan Women's Hairstyles and Plait Decorative Elements: a Historical and Ethnographic Essay
}

\author{
Elena V. Aiyzhy ${ }^{1}$, Rolanda B. Khovalyg ${ }^{2}$ \\ ${ }^{1}$ Tuvan State University (36, Lenin St., 667000 Kyzyl, Russian Federation) \\ Cand. Sc. (History), Associate Professor \\ iD 0000-0002-4289-3543. E-mail: aiygy@mail.ru \\ ${ }^{2}$ Aldan-Maadyr National Museum of the Tyva Republic (30, Titov St., Kyzyl 667000, Russian \\ Federation) \\ Chief Curator \\ iD 0000-0002-6390-7406. E-mail: hovrol@mail.ru \\ (C) KalmSC RAS, 2020 \\ (C) Aiyzhy E. V., Khovalyg R. B., 2020
}

\begin{abstract}
Introduction. The paper studies Tuvan women's hairstyles and plait decorative elements, reveals their typology and features from historical and ethnographic perspectives. Being integral components of both material and spiritual cultures, such decorative elements - through materials and processing techniques, styling patterns, plots and symbols, terminology and worldview attitudes sustainably retain valuable historical and ethnographic messages, original semantics. Goals. The work aims at exploring Tuvan traditional hairstyle types and related plait covers in historical and ethnographic aspects, thus gaining insight into most ancient beliefs and cults, customs and rites, ethnogenetic and ethnocultural ties between Central Asian peoples at large. To date, such typologies and ethnocultural parallels in the realm of traditional hairstyles and decorative elements have been either left aside or examined on a piecemeal basis only. So, insufficiency of actual data and the increasing interest towards Tuvan ethnic culture make the study relevant enough. Methods. The study employs modern interdisciplinary methods and implements an integrated approach that includes methodological principles of related scientific disciplines, such as history, archeology, and ethnography. The research at the intersection of several humanitarian disciplines helps obtain richer information on certain culture-specific features and their functioning principles within the Tuvan ethnos. Results. The paper summarizes results of ethnographic studies, analyzes field and archival materials, and classifies women's hairstyles and plait decorative elements of Tuvans from the late $19^{\text {th }}$ to the $21^{\text {st }}$ centuries. Conclusions. Thus, the article attempts to compile a typology, and describes some elements of ritual practices, especially ones dealing with Tuvan women's hairstyles.

Keywords: women's hairstyle types, men's hairstyles, decorative elements, plait covers, TurkoMongols, Tuvans

Acknowledgements: The reported study was funded by RFBR, project number 19-012-00073.

For citation: Aiyzhy E. V., Khovalyg R. B. Tuvan Women's Hairstyles and Plait Decorative Elements: a Historical and Ethnographic Essay. Oriental Studies. 2020. Vol. 13. No. 1. Pp. 64-74. (In Russ.). DOI: 10.22162/2619-0990-2020-47-1-64-74
\end{abstract}




\section{Введение}

В культурах многих народов мира присутствуют представления о сверхъестественных свойствах волос, которые связаны с мировоззренческим и ритуальным комплексами, характерными для этнических культур. Согласно традиционным представлениям ряда народов Сибири, особые свойства имеют волосы женщин, находящихся в детородном периоде - это определено функцией женщины, производящей на свет детей, что связывает ее магическим образом с иным миром. Магическое значение волос отражено в обычае, сведения о котором приводят Н. И. Клюева и Е. А. Михайлова: «Женщина бесплодная или родившая детей, впоследствии умерших, получала презрительное прозвище „куу баш“ („высохший череп“, то есть „лишенная волос“)) [Клюева, Михайлова 1988: 126].

Поскольку волосам приписывалась особая магическая сила, то считалось, что жизнь ребенка (его душа ${ }^{1}$ ) находится в опасности до того, пока у него не отрастут волосы, и до проведения обряда стрижки первородных волос к голове ребенка запрещалось дотрагиваться незнакомым людям, при этом первородным волосам приписывалась особая охранительная функция. У тувинцев существовал также обычай помещать небольшой пучок из волос младенца в безопасное место в охранительных целях для «сохранения жизни» ребенка [Айыжы 2015: 418].

В культуре тувинцев волосам приписывались свойства являться субстанцией, посредством которой может производиться магическая передача как вредоносного, так и положительного начала. Вследствие этих представлений у тувинцев, как и у многих других народов, бытовал обычай прятанья вычесанных волос, что наблюдали этнографы во время экспедиционных работ в Туве, Монголии и Китае. Вместе с тем вера в возможность осуществления действий контактной или имитативной магии с целью получения счастья и некоторых положительных качеств от других людей обуслови-

${ }^{1}$ Как отмечал С. А. Токарев, душа - это невидимое уязвимое место человека, ее местом обитания часто считается голова [Токарев 1990: $115]$. ла появление ряда специфических обычаев и обрядов, к примеру, обрядовых действий в период свадьбы, в которых внимательно выбирали человека, который будет заниматься причесыванием невесты.

Универсальность и этническая специфика прически

Коса - самая удобная и самая первая прическа, которую придумал себе человек. Косы характерны для культуры народов разных стран мира на разных этапах развития общества. Таинство плетения косы начиналось после того, как руками делили волосы на равномерные пряди. И хотя плетению косы характерны некоторые общие действия, все же у каждого народа присутствуют свои традиции и обычаи в отношении кос и накосных женских украшений, причесок, создающих неповторимые образы.

Прически тюрко-монгольских народов Центральной Азии в разные периоды мировой истории упоминаются в письменных источниках. Так, в средневековье косы носили не только женщины, но и мужчины-монголы. Издревле коса была популярна и у мужчин-тюрков, что подтверждают каменные изваяния древнетюркского периода (VI-VIII вв.), в которых воины изображены с одной косой на спине, аналогичной тувинской мужской прическе кежеге. До начала XX в. тувинцы носили прическу кежеге. Ф. Я. Кон писал по данному поводу, что волосы на голове мужчины спереди сбривают, а сзади заплетают в одну косу, на бороде выщипывают, а усы сверху подбривают, так что верхний край составляет прямую линию (см.: [Кон 1934: 108]).

С. И. Вайнштейн обнаружил в работе Г. Рубрука свидетельство того, что мужчины-монголы выбривали себе на макушке головы четырехугольник и с передних углов вели бритье макушки головы до висков, а в углах затылка оставляли волосы, из которых заплетали косы, завязывая их узлом до ушей [Вайнштейн 1991: 187].

По мнению исследователя Центральной Азии Г. Е. Грумм-Гржимайло, прически в виде косы были введены в Китае маньчжурами во второй половине XVII в., они символизировали подданство Цинской империи [Грумм-Гржимайло 1930: 413].

Тувинские замужние женщины заплетали волосы в две косы, а девушки — в три, со- 


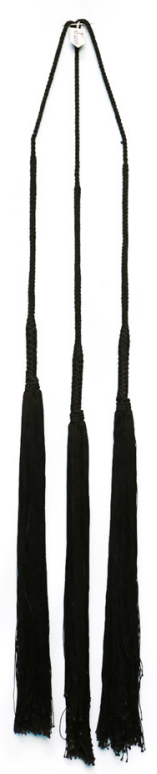

Puc. 1. Боошкун для мужской прически кежеге

Fig. 1. Booshkun for the kezhege male haircut]

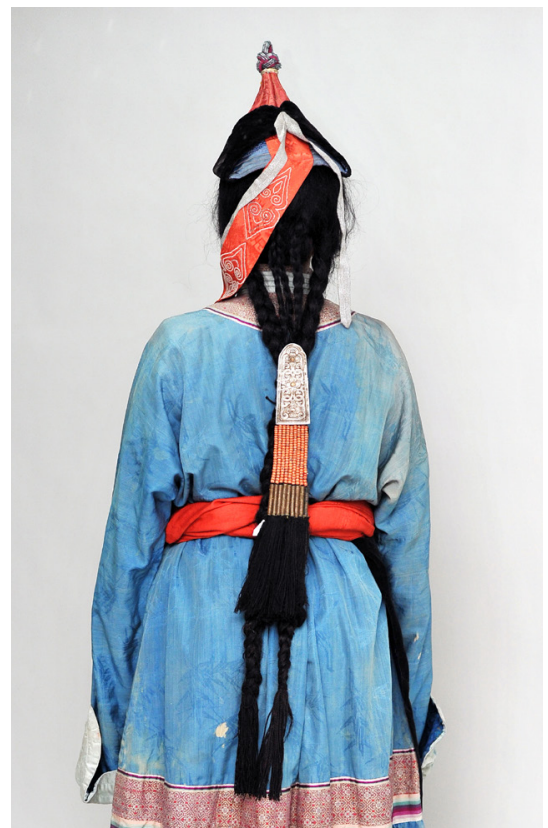

Puc. 3. Сотрудник НМ РТ Б. Ч. Иргит демонстрирует прическу тувинок с использованием экспонатов музея. Фото С. М. Еловикова. 2014 г.

[Fig. 3. Museum worker B. Irgit demonstrates a Tuvan traditional female hairstyle with the use of exhibit items. Photo by S. Elovikov, 2014]

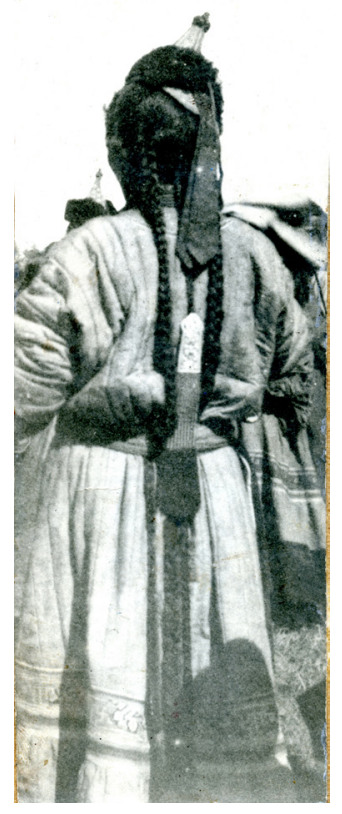

Puc. 2. Заплетание волос замужней женщины в местности Чадаана.

Фото В. П. Ермолаева. НМ РТ, КП-11286/188

[Fig. 2. Married women's plaits, Chadaana locality. Photo by V. Yermolaev]

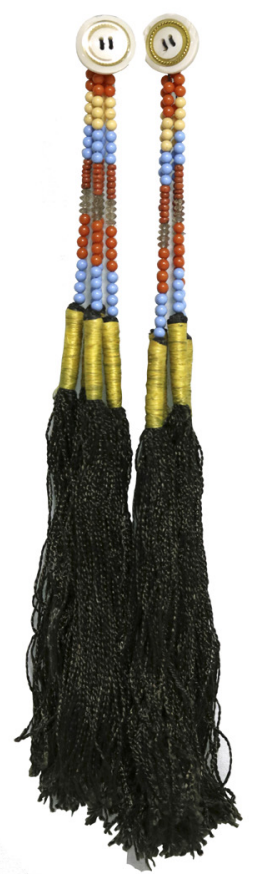

Puс. 4. Салбактар - девичьи накосные украшения. НМ РТ, КП-9566/1-2

[Fig. 4. Salbaktar - maiden plait decorative elements] 
единяя затем их в одну косу. Как мужчины, так и женщины вплетали в косы шёлковые чёрные нитки и завязывали искусственную косу из черного шелка. Данная прическа была характерна для народов центральной Азии.

В дореволюционной Туве в начале XX в. основными накосными украшениями тувинцев являлись салбактар, чавага и гребни [Ховалыг 2018: 121]. При этом и мужчины, и дети завязывали волосы специальным способом боошкун ${ }^{2}$.

Прически у тувинских женщин различались в зависимости от местных традиций, социального положения и возраста. В одних местностях Тувы молодые девушки носили одну косу, в других - три косы, в-третьих - многочисленные мелкие косы. Эти отличия зафиксированы в работах ученых Тувы.

Так, о прическе тувинцев-тоджинцев Б. К. Шишкин оставил следующие свидетельства: сойоты носили косы, гордостью урянхайца также являлась длинная коса, при этом спереди волосы на голове мужчины выбривали (с помощью ножей), а трогать косу и тем более дергать за косу означало нанести оскорбление мужчине. Незамужние женщины обычно заплетали три косы, замужние - две. Тоджинцы - и мужчины, и женщины - вплетали в косы шелковые черные нитки и прикрепляли искусственную косу из черного шелка [Шишкин 1914: 145]. В работе Б. К. Шишкина, представляющей важный источник, обращаем внимание на указание, что шелковые нити называли бээжин-кара ('черные шелковые нити') ввиду того, что тувинские женщины приобретали их у китайских купцов [ПМА: Л. К. Куулар]: слово бээжин происходит от названия города Пекин. Таким образом, в названии нитей зафиксирован факт доставки самих нитей, использовавшихся в прическе, из Китая (г. Пекина). С помощью этих черных шелковых нитей улучшали качество прически - удлиняли и утолщали длину косы для красоты, т. е. создавали искус-

\footnotetext{
${ }^{2}$ Боошкун - завязка для кос, состоящая из трех длинных пучков, сплетенных из черных или разноцветных нитей, заканчивающихся бахромой. У начала бахромы в пучки вплетены кусочки дерева для удобства при завязывании косички.
}

ственные косы, называвшиеся чалаа-кара.

Следует отметить, что женщины из восточной части Тувы, Тоджинского кожууна, в дореволюционное время носили три косы до замужества, а кунгуртугские женщины носили три косы после замужества [Ховалыг 2018: 122]. Есть сведения о ношении трех кос после свадьбы женщинами Тере-Хольского кожууна до начала ХХ в.

Одним из важных источников изучения причесок тувинских женщин является фотоархив В. П. Ермолаева из Национального музея им. Алдан-Маадыр Республики Тыва (далее - НМРТ), материалы которого наглядно свидетельствуют о том, что тувинские женщины заплетали волосы в две толстые косы с двух сторон и между ними на затылке - три мелкие косы сырбык чаш или сай чаш. В волосы вплетали искусственные косы чалаа-кара из черных шелковых нитей, к мелким косичкам сырбык чаш закрепляли накосное украшение чавага таким образом, чтобы оно начиналось с середины косы. Концы кос, чтобы не мешали при хозяйственных работах, закрепляли, пропустив их под поясом. Скорее всего, так плели волосы в западных кожуунах, о чем свидетельствуют деревянные скульптуры, изображающие женщин-тувинок, выполненные основоположниками современного камнерезного искусства Хертеком Коштаевичем Тойбу-Хаа и Донгаком Чамааевичем Окаанчыком.

В западной части Тувы, в Монгун-Тайгинском кожууне, после обряда стрижки утробных волос, начиная с трехлетнего возраста и до 15 лет девочки до проведения обряда myxmen (букв. 'сватовство'; вообще сватовство называли дүгдээр или дүгдээикин) [Потапов 1969: 238] носили одну косу, а после проведения этого свадебного обряда заплетали две косы. Л. П. Потапов отмечал, что имеются определенные различия в обычаях, связанных с прической девушек: тувинцы долины Улуг-Хема, как монголы, хакасы и алтайцы, заплетали раньше девушкам волосы в несколько мелких косичек.

\section{Женские накосные украшения}

Обратимся теперь к женским накосным украшениям. Их условно можно разделить на три группы: девичьи, невесты и замужней женщины.

В фондах Национального музея Республики Тыва хранятся девичьи накосные украшения салбак, выполненные в 90-х гг. 


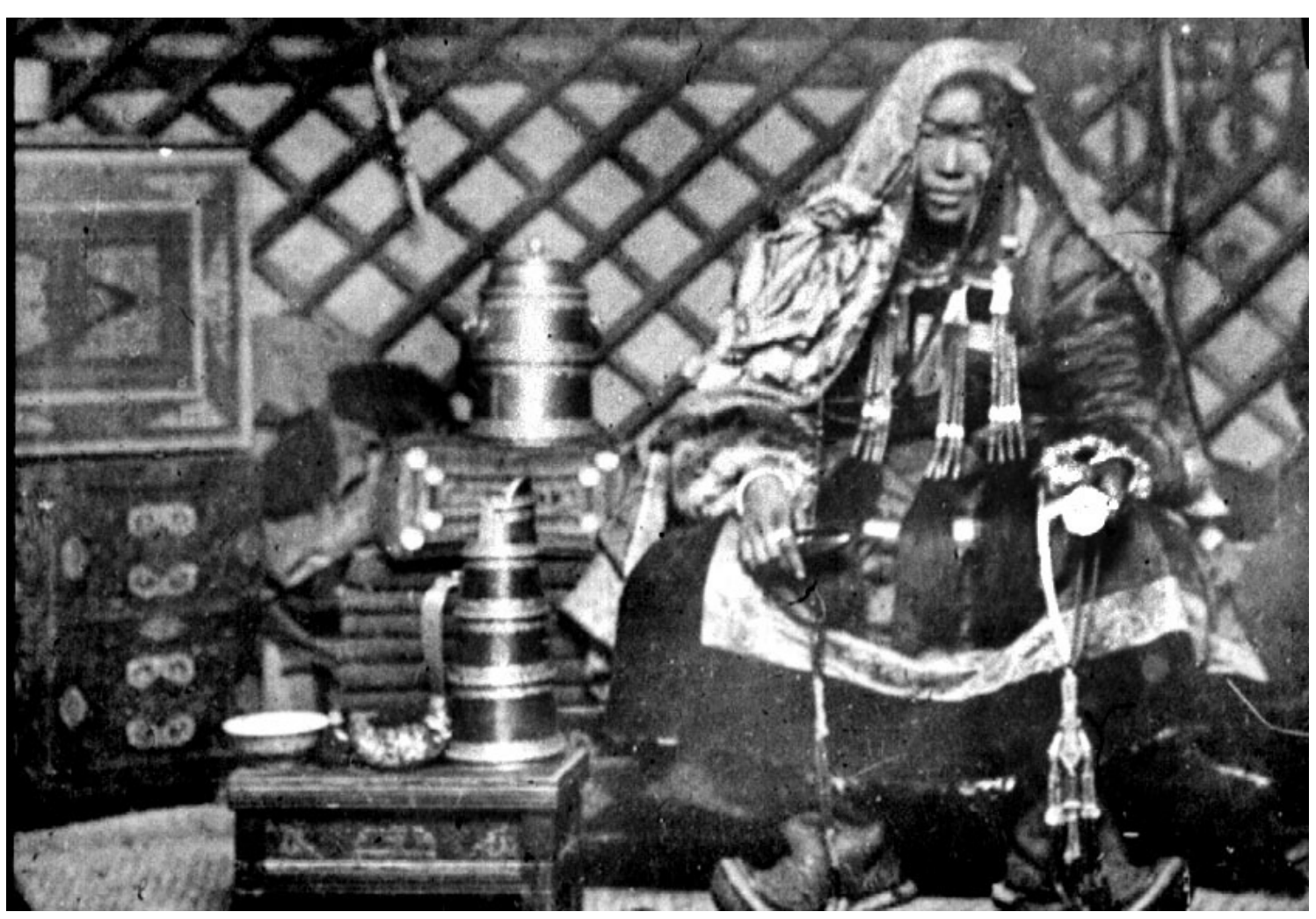

Рuc. 5. Фото Ф. Я. Кона «Богатая невеста из Самагалтая», конец ХІХ в. НМРТ, КП 11286/917

[Fig. 5. Photo by F. Kon 'A Rich Bride from Samagaltai', late $19^{\text {th }} \mathrm{c}$.]

XX в. По сведениям информантов [ПМА: Л. К. Куулар; ПМА: Е. Ш. Байкара], салбак - это накосные украшения девушек, которые носят после обряда дүгдээшкин до свадьбы. К сожалению, другие сведения об этих накосных украшениях в работах ученых-исследователей не встречались. Только в работе С. И. Вайнштейна отмечается, что женщины и девушки, а иногда и мужчины, вплетали в волосы шелковые черные нити бээжсин-кара и сплетали их в длинные искусственные косы чалаа-кара, богатые же женщины дополняли их снизками из коралловых бус - салбак [Вайнштейн 1991: 183].

В некоторых местностях Тувы использовали в качестве накосного украшения чавага. Эти украшения можно увидеть на фотографии Ф. Я. Кона «Богатая невеста из Самагалтая» (фоторепродукция В. П. Ермолаева, из фондов НМРТ, КП-11286/917). Судя по фотографии, в южных кожуунах Эрзин и Тес-Хем замужние женщины заплетали волосы в мелкие косички и на концах каждой косички прикрепляли салбак.

Л. П. Потапов, подробно описывая свадебные обряды тувинцев Монгун-Тай- гинского кожууна, отмечал, что не встречаются сведения о таких девичьих накосных украшениях, как салбак и боошкун. В ходе проведенного сравнительного анализа им было выявлено, что во время обряда (дүгдээшкин) у тувинцев, живущих в верховьях реки Алаш Барун-Хемчикского кожууна, перед тем, как невесте заплетать косы, возле юрты расстилали простеганный нитками войлок (ширтек), на который набрасывали подстилку для сидения кудус (тоже войлок, но обшитый материей, с широким кантом по краям из материи другого цвета). На подстилку усаживали рядом жениха (справа) и невесту (слева), после чего левую руку жениха и правую руку невесты связывали шерстяной ниткой и смазывали им руки топленым маслом. Мать невесты заплетала ей волосы в прическу замужних женщин, в три косы (две на висках и одну толстую сзади, к которой приплетались закинутые назад косы с висков). По данным информантов Л. П. Потапова, в некоторых районах заплетали две толстые косы с обоих боков головы и закидывали их назад, связав концы, между которыми сзади за- 
плетали три маленькие косички, к ним подвешивали украшение чабага (или чавага), которое носили только замужние женщины [Потапов 1969: 246].

По сведениям наших информантов [ПМА: Л. С. Айыжы], чавага - женское накосное украшение, надеваемое на невесту, независимо от того, была ли у нее близость с женихом до свадьбы. Украшение символизировало изменение статуса девушки, то, что она уже стала женщиной. Чавага считалось дорогим украшением ${ }^{3}$ ввиду того, что некоторые элементы изготовлены из серебра и его нужно было заказывать кузнецам-ювелирам. Кроме того, данное украшение передавалось по наследству от матери к дочери. Обычай предписывал отдавать его младшей дочери, но если к моменту выдачи замуж старшей дочери родители не имели материальной возможности сделать новое чавага, они отдавали его этой дочери в надежде, что к замужеству следующей дочери сумеют заказать новое. О том, что изготовление чавага было для некоторых семей затруднительным, свидетельствует то, что иногда родственники жениха помогали в его изготовлении (привозили отдельные части этого украшения с тем, чтобы использовать их при изготовлении полного комплекта).

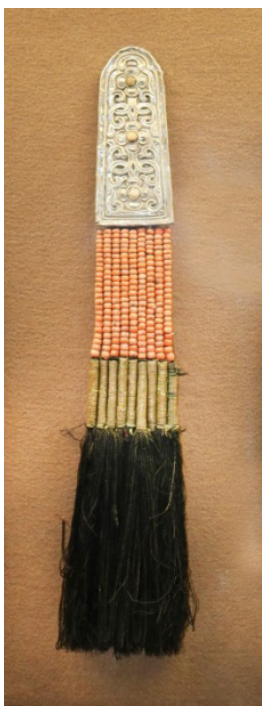

Рис. 6. Чавага - женское накосное украшение (замужних женщин)

[Fig. 6. Chavaga - married women's plait decorative element]

${ }^{3}$ Далее дана характеристика материалов для изготовления чавага.
Основу чавага составляла серебряная пластинка, нашитая на кусок кожи и украшенная жгутами из ниток и снизками из коралловых бусин. В фондах Национального музея им. Алдан-Маадыр Республики Тыва имеются всего 4 (четыре) экземпляра подлинных чавага. Все они однотипны: состоят из плоской серебряной пластинки чавага дөзү, прикрепленной к кожаной полоске. Серебряная пластинка богато орнаментирована гравировкой и чеканкой, с инкрустацией драгоценными камнями (нередко серебряная пластинка крепилась на железной основе). Снизу к серебряной пластинке (к кожаному основанию) прикреплены 9-12 рядов из коралловых бус, 9-12 пучков из черной нити чалаа-кара, скрученных в медную проволоку и заканчивающихся черной бахромой [Ховалыг 2018: 124].

Еще одним интересным моментом является то что, тувинские мужчины, как и дети, завязывали кончики волос в прическе кежеге завязкой боошкун, только у мужчин материал для боошкун делали из простых черных нитей, а у детей — из разноцветных нитей.

Таким образом, в тувинской культуре конца XIX - начала XX в. девочки в возрасте от 13 до 15 лет, т. е. до замужества, заплетали волосы в одну косу в западной части Тувы (Дзун-Хемчиксий, Овюрский, Сут-Хольский, Барун-Хемчикский и Бай-Тайгинский кожуунах), в две косы - в южных кожуунах (Тес-Хемский, Эрзинский), в три косы - в Монгун-Тайгинском, Тоджинском кожхуунах (восточная Тува), в мелкие косички - в Улуг-Хемском кожууне (Центральная Тува). При этом они носили самое простенькое накосное украшение боошкун. Во время обряда сватовства дүгдээикин девушкам заплетали волосы в две косы и прикрепляли к ним девичьи накосные украшения из разных бус салбактар.

Представления тувинцев о волосах и манипуляциях с ними связаны с приписыванием им различных символических и даже магических значений, что характерно для культур разных народов мира с древнейших времен. При этом отношение тувинцев к волосам было очень внимательное, «аккуратHое».

Рассмотрим специфический обряд тувинцев - myxmen, проводившийся во время одного из свадебных обрядов дугдээшкин, во 
время которого соединяли кончики кос жениха и невесты и заставляли их угадывать, кому принадлежат волосы, показывая лишь их концы. Содержание данного обряда следующее: из юрты, где сидели рядом жених и невеста, просили всех выйти. С молодоженами оставляли одного из родственников (обычно со стороны невесты) - мужчину или женщину. Этот человек брал концы кос жениха и невесты, расчесывал их гребнем, затем соединял, зажав в свой кулак, и показывал молодым лишь кончики соединенных волос, заставляя их угадывать, где волосы каждого из них. В это время родственники с обеих сторон (жениха и невесты) подглядывали в щели юрты, следя за тем, как все это происходит и нет ли тут какого-либо подвоха. Если жених угадывал, где кончики волос его невесты, а невеста узнавала, где в пучке волосы своего жениха, то это считалось предзнаменованием того, что брак этот будет удачным и счастливым. Если, напротив, жених и невеста опознавали только каждый свои волосы, то родственники и сами молодожены расстраивались, хотя брак от этого обряда не распадался.

Прическа в обрядах жизненного цикла

В ходе полевых исследований нами выявлено, что знаковой маркировкой возраста у тувинских женщин было изменение причесок на разных этапах жизни. При этом имелись варианты ее изменений, обусловленные этническими, локальными и другими факторами.

Всего у тувинских женщин можно выделить семь видов причесок в обрядах жизненного цикла.

1. Детская прическа. Первыми ритуальными манипуляциями с волосами ребенка являлась «стрижка утробных волос», которая часто осуществлялась на 2-3 годах жизни ребенка, часто и позже, в возрасте до пяти лет (для мальчиков этот обряд предпочитали проводить в нечетные годы их жизни, а для девочек - в четные). Центральная Азия находится в зоне традиций, где предписывается оставлять при первой стрижке у ребенка определенную часть волос, выбривая (выстригая) остальные. Эта традиция, по всей видимости, очень древняя, поскольку охватывает широкий круг культур: тунгусо-маньчжурские народы, монгольские, тюркские, иранские, в том числе и припамирские народности. Д. Баяр, исследовавший прически средневековых монголов, отметил существование обычая частичного бритья головы у сяньбийцев и ухуаней (1 половина I тыс. н. э.) [Баяр 1993: 113]. Анализ имеющихся материалов о детях у народов Центральной Азии позволяет сделать вывод о том, что в конце XIX в. преобладала традиция не подчеркивать пол детей младшей возрастной группы ни в одежде, ни в головных уборах, ни в прическе; и девочку, и мальчика называли чаш уруг ребенок. Наиболее распространенный вариант детской прически был таким: один или два пучка волос оставляли на каждом виске, один пучок волос - на темени или затылке. В редких случаях прическа различалась по полу, и в этом случае варианты сходные: девочкам оставляли пучки на висках и темени, а мальчикам - только на темени либо девочкам - лишь на висках, мальчикам - лишь на темени. Примерно такие детские прически фиксируются у ряда народов южной Сибири. Так, у теленгитов оставляли волосы девочкам на висках и темени, а мальчикам - только на темени (считалось, что мужчина должен оставлять эти волосы всю жизнь). Данный обычай был зафиксирован у хакасов и тувинцев [Клюева, Михайлова 1988: 118].

Обряд первой стрижки должен начать дядя по линии матери, что отражает особое отношение дяди к его племянникам, детям сестры. Кроме того, каждый присутствующий приглашенный также совершал отрезание пряди волос. Перед тем как совершить прикосновение к детским волосам, каждый участник обряда должен был попробовать «белую», сакральную «пищу» в виде молока, что объяснялось очистительной силой белой молочной пищи. Предохранительные действия заключались также в окуривании дымом можжевельника ножниц - считалось, что этим ребенка защищали от сглаза и порчи.

Отрезание пряди волос у ребенка каждым из участников обряда, начиная с дяди по матери, сопровождалось произнесением благопожелания в адрес ребенка и его родителей и одариванием ребенка; прядь волос помещали в специальный мешочек, привязанный к ножницам, в котором они впоследствии и хранились. Подарки могли быть различной ценности: либо скот (лошади, коровы, овцы), либо шкуры барашка, 
сурка, одежда, молочные продукты или сладости, либо хадак. Одаривать могли и деньгами. Скот, подаренный ребенку, становился основой его будущего хозяйства. Обряд стрижки волос завершался трапезой. Если же старший дядя по материнской линии не мог присутствовать на обряде по уважительной причине, то с целью проведения им знаковых действий оставляли специально нестриженой прядь волос на голове и не трогали ее в течение трех дней.

Тувинцы сомона Цэнгэл Баян-Ульгийского аймака Монголии обряд стрижки утробных волос у мальчика проводили в три года, у девочки - в два или четыре года. В особых случаях, когда ребенок болел, срок стрижки утробных волос переносили на более поздний период, например до пяти лет; но считается, что после пяти лет «волосы отяжелеют». Собирали родственников по принципу чьлы каржы эвес торелдери ('не жесткие по годам родственники'), то есть соответствующие по годам (по лунно-солнечному календарю 12-летнего животного цикла) согласно традиционной астрологии. Обязательным моментом является то, что проводил данный обряд хылбык альр кижи ('человек, который будет стричь первые волосы ребенка') или хол дээр кижи ('человек, который первым дотронется до волос ребенка'). Начинал он со словами чаа, ам киживистин хылбыьлн хоюзар бис бе? ('давайте начнем стричь волосы?'). Ребенка просили встать, сначала притрагивались до волос деревянным ножом. Потом произносили следующие фразы Кезер дээш кеспедим. Кезер-Богданын чарлыьындан кестим. Альр дээш албадым. Богда-ламанын айыткан ёзузундан алдым ('Хотел стричь, да не стал этого делать. А стал стричь по указу Богда-лама. Хотел взять, да не стал этого делать. А взял по указанному обычаю Богдо-лама'). После этих слов участник обряда брал ножницы, к концам которых привязан белый хадак, окуренный дымом можжевельника и смазанный топленым маслом и молоком. Полагалось по направлению движения солнца состричь 2-3 пучка волос ребенка, отрезанные волосы поместить на белую ткань. Каждый подходивший для совершения этого обряда произносил благопожелания: Haзы-хары узун болзун. Ада-иезинге ачь-буянныг болзун ('Пусть возраст будет длинным. Родителям будет полез- ным`), Узун назынныг, удаан чыргалдыл эки эр болзун ('Пусть достигнет преклонного возраста и умрет во сне') и т. п. В качестве подарков дарили: мальчику жеребенка, девочке - телёнка.

Тувиниы Кобдоского аймака Монголии в проведении данного обряда придерживаются особенностей. Обряд стрижки утробных волос называли хылбыылн шылжсаар, хылбыblн хойзур ('хранить утробные волосы', 'отпугивать [нечистую силу] от утробных волос'). Если ребенок болел в период проведения обряда, то переносили обряд на пятилетие, и в год достижения ребенком 5 лет обязательно проводили обряд, считая, что хылбыь аартаар ('утробные волосы отяжелеют $\left.{ }^{6}\right)$. В назначенное ламами время обряд проводили до обеда, так как после обеденного дня главные событийные празднества не совершают.

2. Прическа девочки, достигшей половой зрелости. Важнейший этап в жизни девочки - достижение половой зрелости, который мог быть отмечен семейным торжеством, во время которого происходила и смена головного убора, и смена прически: волосы заплетали в одну косу, после чего запрещалось их стричь. Семантика данного действия заключалась в символическом накоплении жизненной энергии, что чрезвычайно важно для женщины - продолжательницы рода. Девушкам до замужества символически заплетали одну косичку чаш [чаъш] и завязывали ее концы украшением из бус боошкун, что означало свободное положение молодой девушки;

3. Прическа просватанной девушки. В день сватовства дополнительную вторую косу девушке заплетала родственница с материнской стороны, что символизировало: девушка занята, сосватана. Во время обряда дугдээшкин (когда жених приезжал с родственниками познакомиться с родственниками невесты) мать просватанной девушки заплетала дочери волосы в две косы и крепила к ним парные накосные украшения салбактар. На макушку головного убора невесты крепили длинную, из красных шелковых ниток, кисть маак, которая опускалась на спину. Это означало, что она сосватана, имеет жениха, обрела пару.

4. Прическа замужней женщины. В день свадьбы волосы невесты заплетали с украшением чалаа-кара в виде трех черных ко- 
сичек. После свадьбы замужние женщины заплетали волосы в две толстые и три мелкие сырбык, сай чаштар 4 косы: две толстые косы символизировали статус замужних женщин, накосное украшение посередине чавага являлось знаком семьи.

5. Пожилые замужние женщины заплетали две косы и, связав их концы, помещали за пояс.

6. Женщин, которые до старости дожили без детей и мужа, называли дулгуяк, они носили одну косу кежеге, как мужчины;

7. Женщин возраст старше 65-75 лет называли шуваганчы, они обычно сбривали волосы налысо.

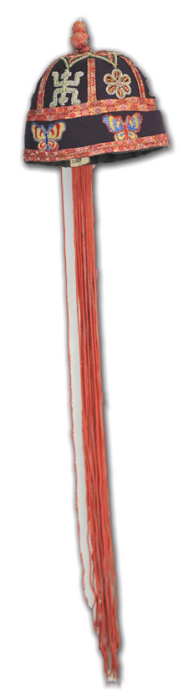

Puc. 7. Шапка с красными кистями просватанной невесты

[Fig. 7. Hat with red tassels of a betrothed maid]

\section{Полевые материалы авторов}

ПМА: Айыжы Л. С. - Айыжы Л. С., 1946 г. р. Уроженка м. Баян-Дугай Дзун-Хемчикского кожууна. В настоящее время проживает в г. Кызыле.

ПМА: Байкара Е. Ш. - Байкара E. Ш., 1929-2008 гг., уроженка с. Баян-Кол Пий-Хемского кожууна, работала научным сотрудником Национального музея Республики Тыва

ПМА: Куулар Л. К. - Куулар Л. К., 1955-2008 гг., уроженка с. Суг-Аксы Сут-Хольского кожууна, работала научным сотрудником Национального музея Республики Тыва.
В отношении волос в традиционной культуре тувинцев существуют следующие приметы и поверья, которые соблюдаются и по сегодняшний день: обряд стрижки утробных волос следует совершать по достижении ребенком трех лет; стрижку волос следует совершать в благоприятные дни по лунному календарю; после захода солнца нельзя стричь волосы; после расчесывания и стрижки волос нельзя бросать волосы.

\section{Заключение}

Исследование причесок и накосных украшений тувинцев показывает, что в их культуре прослеживаются как характерные для ряда народов Центральной Азии и Южной Сибири черты, так и локальные характеристики. В традициях субэтнических групп и районов Тувы имелись особенности, которые отличали их от других. Вместе с тем можно выявить семь основных типов причесок девочки и женщины, которые являлись маркерами возрастных групп. Накосные украшения также отличались спецификой для разных возрастных групп и маркировали статус девушки и женщины. Как отмечал А. К. Байбурин, любая вещь, созданная человеком, обладает как утилитарными, так и символическими свойствами. В этом плане украшения содержат минимум «вещности» и максимум знаковости [Байбурин 1989: 63-87]. В целом прически и украшения являлись неотъемлемой частью обрядовой системы, оформлявшей жизненный цикл человека; они имели глубокое смысловое содержание, изучение которого способствует расширению знаний о традиционной культуры тувинского этноса.

\section{Литература}

Айыжы 2015 - Aйыжы E. B. Категория «возраст» и отношение к нему у тувинцев. // Казанский педагогический журнал. 2015. № 5-2. С. 415-421.

Байбурин 1989 - Байбурин А. К. Семиотические аспекты функционирования вещей // Этнографическое изучение знаковых средств культуры. Л.: Наука, 1989. С. 63-88.

Баяр 1993 - Баяр Д. Прически монголов в XIIIXV вв. // Из истории хозяйства и материальной культуры тюрко-монгольских народов. Новосибирск: Наука, 1993. С. 113-124.

\footnotetext{
${ }^{1}$ Сырбык, сай чаштар - символ материнства и детей.
} 
Вайнштейн 1991 - Вайнштейн С. И. Мир кочевников Центра Азии. М.: Наука, 1991. $294 \mathrm{c}$.

Грумм-Гржимайло $1930-$ Грумм-Гржимайло $\Gamma$. E. Западная Монголия и Урянхайский край. Т. 1-3. СПб.: Невская типография, 1914-1930. 4 т. Антропологический и этнографический очерк этих стран; Торговая и колонизаторская в них деятельность китайцев и русских. 1930. [2], II, 413-858, [1] с.

Кон $1934-$ Кон Ф. Я. За пятьдесят лет: собр. соч. в 3 т. М.: Изд-во Всес. о-ва политкаторжан и ссыльно-поселенцев (тип. Профиздата), 1932-1934. 294 c.

\section{Authors' Field Data}

Informant: Aiyzhy L. S., b. 1946, native to BayanDugay village (Dzun-Khemchiksky District, Tyva Republic). Currently lives in Kyzyl. (In Tuv. and Russ.)

Informant: Baykara E. Sh., 1929-2008, native to Bayan-Kol village (Piy-Khemsky Dustrict, Tyva Republic). Worked as a researcher at the Aldan-Maadyr National Museum. (In Tuv. and Russ.)

Informant: Kuular L. K., 1955-2008, native to Sug-Aksy village (Sut-Kholsky District, Tyva Republic). Worked as a researcher at the Aldan-Maadyr National Museum. (In Tuv. and Russ.)

\section{References}

Aiygy E. V. Category 'age' and the attitude of the Tuvans towards it in the traditional culture. Kazan Pedagogical Journal. 2015. No. 5-2. Pp. 415-421. (In Russ.)

Bayar D. Haircuts of Mongols: $13^{\text {th }}-15^{\text {th }}$ centuries. In: [Economy and Material Culture of TurkoMongols: Glimpses of History]. Novosibirsk: Nauka, 1993. Pp. 113-124. (In Russ.)

Bayburin A. K. Functioning of things: semiotic aspects. In: [Ethnographic Studies in SymbolicCultural Means]. Leningrad: Nauka, 1989. Pp. 63-88. (In Russ.)
Клюева, Михайлова 1988 - Клюева Н. И., Михайлова $E$. M. Накосные украшения у сибирских народов // Сборник Музея антропологии и этнографии. Т. XLII. Л.: Изд-во АН CCCP, 1988. C. 106-128.

Токарев 1990 - Токарев С. А. Ранние формы религии. М.: Политиздат, 1990. 115 с.

Потапов 1969 - Потапов Л. П. Очерки народного быта тувинцев. М.: Наука, 1969. 402 с.

Ховалыг 2018 - Ховальг Р. Б. Тувинская традиционная одежда = Тыва үндезин хеп. Новосибирск: Наука, 2018. 336 с.

Шишкин 1914 - Шишкин Б. К. Очерки Урянхайского края. Томск: Типо-лит. Сиб. т-ва печ. дела, 1914. IV, 327 с.

Grum-Grshimailo G. E. [Western Mongolia and the Uriankhai District]. Vol. 4: Anthropological and Ethnographic Essays; Trade and Colonizing Activities of the Chinese and Russian St. Petersburg: Nevskaya Tipografiya, 1930. Pp. 413-858. (In Russ.)

Khovalyg R. B. [Tuvan Traditional Garments]. Novosibirsk: Nauka, 2018. 336 p. (In Russ. and Tuv.)

Klyueva N. I., Mikhaylova E. M. Peoples of Siberia: plait decorative elements. In: [Museum of Anthropology and Ethnography: Collected Works]. Leningrad: USSR Academy of Sciences, 1988. Vol. XLII. Pp. 106-128. (In Russ.)

Kon F. Ya. [Over the Fifty Years: Collected Works]. In 3 vols. Moscow: Profizdata, 1932-1934. 294 p. (In Russ.)

Potapov L. P. [Sketches of Tuvan Traditional Household Activities]. Moscow: Nauka, 1969. 402 p. (In Russ.)

Shishkin B. K. [Essays on Uriankhai Land]. Tomsk: Siberian Printing Partnership, 1914. 327 p. (In Russ.)

Tokarev S. A. [Early Forms of Religion]. Moscow: Politizdat, 1990. 115 p. (In Russ.)

Vaynshteyn S. I. [World of Nomads Inhabiting Asia's Center]. Moscow: Nauka, 1991. 294 p. (In Russ.). 